AIAA 2003- 4806

Erosive Burning Study Utilizing Ultrasonic Measurement Techniques

James A. Furfaro

ATK Thiokol Propulsion Corp.

Brigham City, UT

$39^{\text {th }}$ Joint Propulsion Conference and Exhibit 20 - 23 July 2003/Huntsville, Alabama 


\title{
Erosive Burning Study Utilizing Ultrasonic Measurement Techniques
}

\author{
James A. Furfaro \\ ATK Thiokol Propulsion, Brigham City, Utah 84302
}

\begin{abstract}
A 6-segment subscale motor was developed to generate a range of internal environments from which multiple propellants could be characterized for erosive burning. The motor test bed was designed to provide a high Mach number, high mass flux environment. Propellant regression rates were monitored for each segment utilizing ultrasonic measurement techniques. These data were obtained for three propellants RSRM, ETM03, and Castor ${ }^{\circledR}$ IVA, which span two propellant types, PBAN (polybutadiene acrylonitrile) and HTPB (hydroxyl terminated polybutadiene). The characterization of these propellants indicates a remarkably similar erosive burning response to the induced flow environment. Propellant burn rates for each type had a conventional response with respect to pressure, $\mathrm{aP}^{\mathrm{n}}$, up 'to a bulk flow velocity threshold. Each propellant, however, had a unique threshold at which it would experience an increase in observed propellant burn rate. Above the observed threshold each propellant again demonstrated a similar enhanced burn rate response corresponding to the local flow environment.
\end{abstract}

\section{INTRODUCTION}

Marshall Space Flight Center and ATK Thiokol Propulsion have worked together on the engineering design of a 5-segment Engineering Test Motor (ETM03). An overview of the design effort and work by everyone involved for ETM-03, which will be the world's largest segmented solid rocket motor, is presented by Huppi, Tobias, and Seiler in Ref 1. ETM03 was designed and created for the purpose of providing a better understanding of RSRM margins, and the techniques and models used to simulate solid rocket motor performance. The enhanced performance of ETM-03 is achieved primarily by the addition of a RSRM center segment. Added motor performance is also achieved with a nozzle throat diameter increase and the incorporation of an Extended Aft Exit Cone (EAEC). Parameters such as web time, action time, head end pressure, web time average pressure, maximum thrust, mass flow rate, centerline Mach number, pressure and thrust integrals have all increased over RSRM. In some cases these increases are substantial. These changes to the environment have been linked to an increased potential for enhanced propellant burn rate. The enhanced propellant burn rate, also referred to as "Erosive Burning", required an engineering assessment for an accurate motor performance evaluation.

Erosive burning is a solid propellant combustion phenomenon in which the local burning rate is enhanced above the base burn rate in the presence of high cross-flow velocities at the burning propellant surface. This burn rate enhancement is typically present only in the very early portion of motor operation and rapidly dissipates as the grain regresses and bore cross-flow velocities decrease. Many solid rocket motors exhibit this condition, especially tactical motors which operate at high flow Mach numbers and length to port diameter ratios (L/D). Generally, erosive burning is a byproduct of motor design constraints and the propellant formulation and not an intentional performance characteristic. In most cases where erosive burning is present, it is simply "managed" or controlled to a level that meets performance constraints. In a few instances, erosive burning can actually provide additional performance that cannot be obtained by other conventional means.

Solid rocket motors that have high length to port diameter ratios and low port to nozzle throat diameter ratios can have the potential for erosive burning since the flow velocities tend to be higher than other motor designs. It is generally accepted that macroscopic erosive burning is not present in the current RSRM, however, there is some evidence to suggest local areas of erosive burning may exist. Certainly, the RSRM does not exhibit any characteristics of large scale, classical erosive burning, thus it can be considered negligible.

Copyright $\odot 2003$ by ATK Thiokol Propulsion, A Division of ATK Aerospace Company,

Published by the American Institute of Aeronautics and Astronautics, Inc. with permission. 
Erosive burning was an area that required further live motor testing experience to be able to provide an accurate engineering assessment. A test methodology was developed for the purpose of providing enhanced burn rate data that could improve ATK Thiokol's inhouse ballistic predictive capabilities. Current in-house ballistic models are based on either an augmented heat transfer from a high cross-flow velocity at the propellant surface or alteration of the transport properties between the propellant surface and the flame zone. These models rely on a historical motor database to evaluate scaling parameters for erosive burning prediction in large motors. The testing covered in this paper has provided additional data for the historical database of motors that exhibit erosive burning and has contributed towards ATK Thiokol's increased understanding of core fluid velocity and motor size influences on propellant erosive burning response. The expanded database has been used to improve in-house 1-D and 2-D CFD erosive burning modeling and predictive capabilities. Wang discusses the 2-D CFD erosive burning prediction enhancements in Ref 2 .

\section{DISCUSSION}

The purpose of this paper is to provide a forum for the dissemination of information collected during erosive burning testing at ATK Thiokol Propulsion Corp. in Promontory, Utah. The work is a continuation of an effort started under Five Segment Booster (FSB) to better understand propellant erosive burning response of RSRM propellant. A summary of the work conducted in support of FSB is contained in Ref 3. Another erosive burning study, which has collected motor data similar to that provided in this report was conducted by Strand, Yang, Nguyen, and Cohen, Ref 4 . Their burn rate data was collected from a segmented subscale test device utilizing plasma capacitance gauges for propellant regression measurements. The author has found the data collected from this work and a journal paper by Merrill K. King reviewing erosive burning techniques titled, "Erosive Burning of Solid Propellants," found in Ref 5, to provide a good overview of the work performed in the area of erosive burning phenomena.

\section{TEST OBJECTIVES}

The main objective of the testing was to generate enhanced burn rate data for the purpose of evaluating the predicted ballistic performance of ETM-03. To accomplish this task, a subscale test device was developed with the following goals:
- Induce repeatable and sustained erosive burning within a subscale test device.

- Develop instrumentation capable of measuring location specific burn rates at multiple points throughout the motor.

- Characterize three propellants composing two types.

Descriptions of these three propellants are summarized in Table 1.

Table 1: Propellant descriptions.

\begin{tabular}{lccc}
\hline & RSRM & ETM-03 & Castor $^{\circledR}$ IVA \\
\hline $\begin{array}{l}\text { Solids Content } \\
(\text { wt\% })\end{array}$ & 86 & 86 & 88 \\
$\begin{array}{l}\text { Binder Type } \\
\text { Normalized }\end{array}$ & PBAN & PBAN & HTPB \\
\begin{tabular}{l} 
Burn Rate \\
\hline
\end{tabular} & -0 & 0.93 & 0.70 \\
\hline
\end{tabular}

"Note: Binder type abbreviations; PBAN (Polybutadiene acrylonitrile) and HTPB (Hydroxyl terminated polybutadiene).

\section{TEST HARDWARE DESCRIPTION AND INSTRUMENTATION}

The subscale test motors were a tandem series of six identical motor segments. Each segment was 5-inches in diameter at the inner case wall and 9-inches in length. A weldment was centered on the case wall to support the ultrasonic instrumentation package. The segment grain geometry consisted of a 2-inch CP (Center Perforated) grain bore with a $1 / 4$-inch by $1 / 4$-inch chamfer cut in the forward edge of the grain bore on all the motor segments, as in Figure 1. The chamfer provided flow relief to prevent flow restriction from occurring due to propellant grain deformation in the high flow Mach environment. The chamfer was cut into all the motor segments to provide a similar flow environment throughout the motor and allow for interchangeability of the motor segments. 


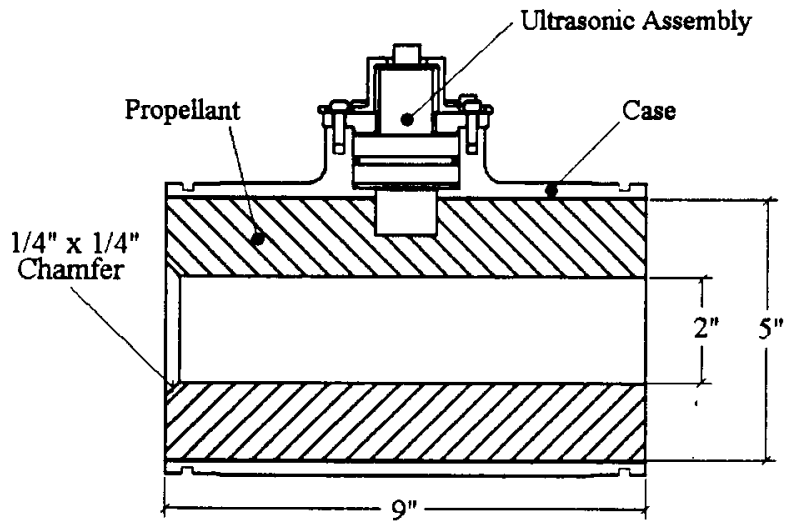

Figure 1: Segment grain dimensions.

The relatively small 2 -inch grain bore diameter was a means to increase internal gas-flow Mach number using a reasonable number of motor segments and size of nozzle throat diameter. Sufficient hardware was made available to allow all motor segments required for a tandem motor test set, which consisted of twelve individual segments, to be cast simultaneously from a single propellant mix. This eliminated any burn rate variation that would be incurred from casting motors from different propellant mixes. Casting both the RSRM and Castor ${ }^{\mathbb{Q}}$ IVA test motors was scheduled to coincide with a full size motor cast to obtain propellant representative of a full size production mix. ETM-03 test segments were cast from a full size verification mix.

Assembly of the tandem test article, shown in Figure 2, consisted of six 5-inch CP motor grains mated with cylindrical rings placed between the motor cases. The mating rings spaced the segments approximately
$1 / 2$-inch apart. The spacing allowed for the faces of the segments to easily ignite and provide pressure port access to the motor chamber. End burning of the $\mathrm{CP}$ motor segments was used to provide a relatively neutral ballistic pressure trace. Three solid threaded metal bars tensioned at the flanges on the forward and aft closures were used to hold the tandem motor assembly together. This assembly was then bolted to a metal table with the nozzle oriented upward. Motor thrust was not measured to prevent the possible loss of thrust stand hardware and instrumentation due to motor failure from the expected harsh internal motor flow environment.

A radial flow igniter loaded with $\mathrm{BKNO}_{3}$ pellets was used to ignite the tandem motor assemblies. This igniter assembly provided adequate and repeatable ignition performance in all the erosive burning tests.

The nozzles were machined from graphite billets of medium-density HML graphite. The nozzle throat diameters for all the tandem tests were machined to 1.942 -inches. This geometry configuration resulted in a port-to-throat area ratio of 1.06 and a theoretical 1-D Mach number of 0.75 in the aft portion of the aft segment.

The relationship between the propellant grain bore area and the nozzle throat area was used to control gasflow Mach number, and the number of motor segments was used to regulate chamber pressure. This was unique to the erosive burning testing and a result of the type of ballistic information desired. In normal motor operation it is the nozzle throat diameter in conjunction with the propellant grain surface area that is used to regulate motor chamber pressure.

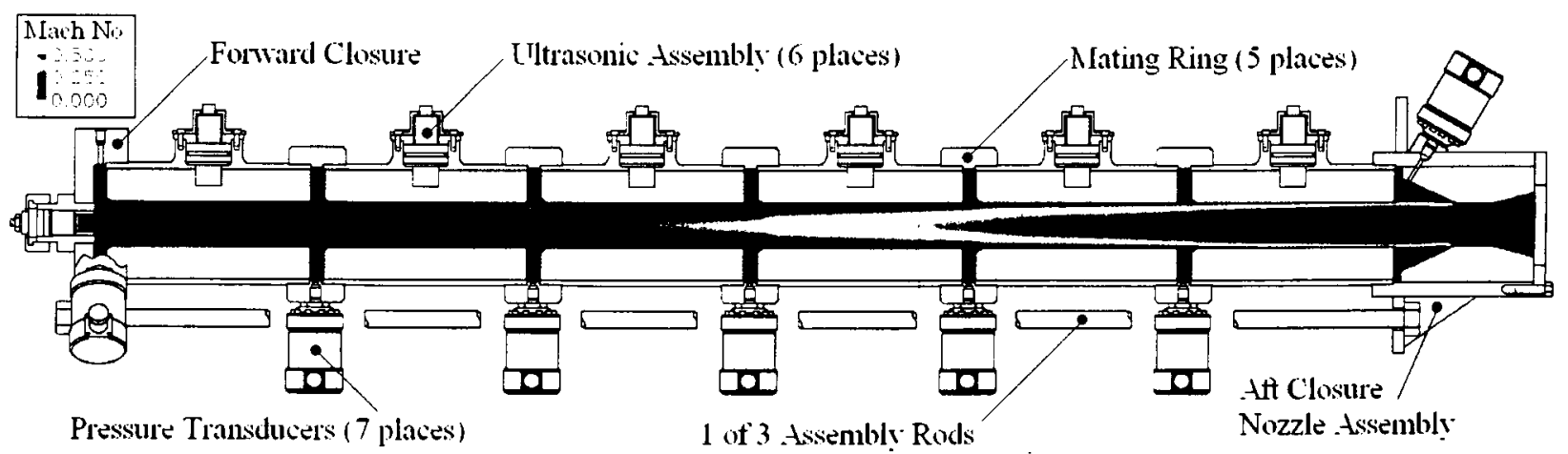

Figure 2: Tandem motor assembly. 


\section{PRESSURE MEASUREMENTS}

A total of seven Taber $^{\circledR} 206$ pressure transducers were used to evaluate axial pressure drop within the motor. One pressure transducer was located in the forward closure, five were distributed along the length of the motor at each mating ring between the segments and the final pressure transducer was located at the entrance to the nozzle. An illustration of the pressure transducer locations is shown in Figure 2.

\section{ULTRASONIC INSTRUMENTATION}

The choice of ultrasonic instrumentation to measure propellant grain surface regression was based on previous success using ultrasonics at ATK Thiokol Propulsion Corp. Past experience includes a similar approach used to measure propellant grain surface regression in a hybrid motor. This work is published in the following papers.

- AIAA 95-3081, "An Ultrasonic Fuel Regression Rate Measurement Technique for Mixture Ratio control of a Hybrid Motor", Ref 6.

- CPIA Publication 616, "Measurement of Fuel Regression Rate in Hybrid Motors Using a Digital Ultrasonic Technique", Ref 7.

The ultrasonic transducers were Panametrics 0.75inch single element $0.5 \mathrm{MHz}$ center frequency, transmit 1 receive transducers. As illustrated in Figure 3, the transducer was located mid-segment and aligned with the centerline of the propellant grain. To maximize the return signal strength the ultrasonic transducer transmitted through an acoustic stack. The acoustic stack was designed to meet two design goals.

- Ability to permit the passage of the acoustic signal.

o Matching the impedance of the propellant.

- Minimize the amount of acoustic energy reflected at each material interface.

- Ability to support motor operational pressure with a suitable design factor

To meet the two design goals of matching impedance and supporting motor operational pressure, Vespel $^{\circledR}$, a Dupont ${ }^{\mathrm{TM}}$ material was chosen for its acoustic properties and its structural capabilities. This material has demonstrated success with other programs. To reduce signal reflection at the Vespel ${ }^{\mathbb{B}}$ surface, an intermediate material was introduced to impedance match the Vespel ${ }^{\otimes}$ with the propellant grain. The chosen material was propellant gum stock. Propellant gum stock is the binding matrix that maintains the structural integrity of the solids in the propellant. The propellant gum stock has the similar acoustic properties as the propellant without the signal scatter degradation from the solid particulates in the propellant.

As an added reduction in signal loss, the material surface between the Vespel ${ }^{\circledR}$ and gum stock was curved to form an acoustic lens. Focusing of the acoustic signal on the propellant grain surface helped to minimize signal scatter from the curved propellant surface. Using all of the techniques presented helped to maximize the allowable propellant web thickness monitored in the erosive burning tests.

The acoustic stack extended into the propellant grain reducing the observable web to $3 / 4$-inch. Reduction of the observable web was necessary to provide an adequate signal to noise ratio for data analysis.

Surface position measurements were taken using the ultrasonic transducers at a rate of $50 \mathrm{~Hz}$ for approximately 2.5 seconds. The return waveform was sampled at a rate of $10 \mathrm{MHz}$ during a $30 \mu \mathrm{sec}$ window. Over the duration of the test, this amounts to 125 windows of recorded data per segment for each tandem test. The limiting factor for the ultrasonic pulse rate was the data acquisition capacity.

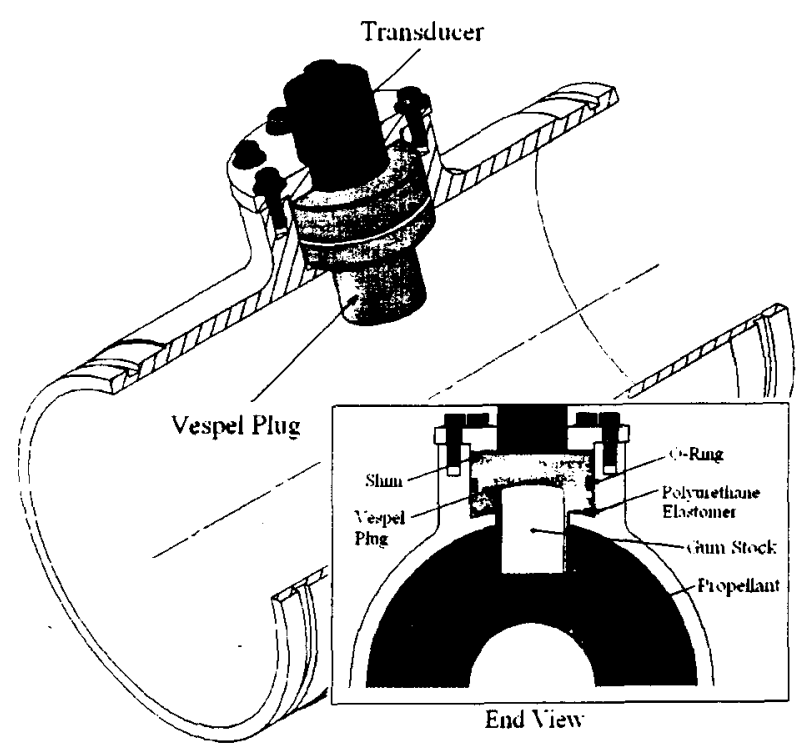

Figure 3: Ultrasonic instrumentation configuration. 


\section{DATA REDUCTION METHODS}

\section{ULTRASONIC BURN RATE EVALUATION}

A sample return waveform is illustrated in Figure 4. It was noted that the window of data acquisition used to capture the return waveforms would drift during the test. To compensate for the drift, the return waveforms were normalized in time by shifting each waveform such that the propellant / gum stock surface reflection was at zero.

After normalizing the waveform with respect to time, the standing wave noise was removed by subtracting the amplitude of the previous waveform from the current waveform. This process leaves only the changing components between time steps. Figure 5 is a waterfall that illustrates the compilation of normalized, reduced waveforms, which traces the progression of the propellant surface. The propellant surface reflection can be seen progressing from the lower right to the upper left hand corner of the figure.

After time normalization and standing wave removal, signal to noise ratio was very good and the propellant surface return signal could be isolated. The next step incorporated an auto-correlation technique to track the propellant surface return signal through the burn time of the observed web. This information was then used to compute the propellant burn rate from a floating nine point linear fit of the surface position measurements.

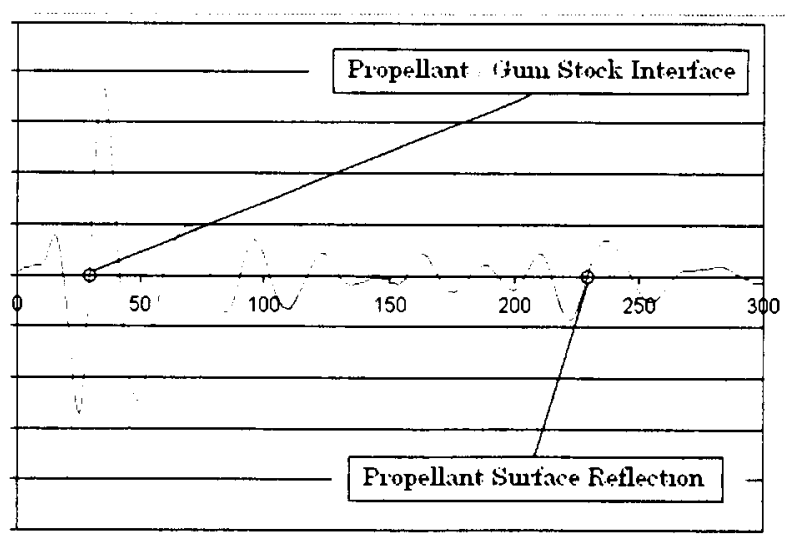

Figure 4: Measured return waveform.

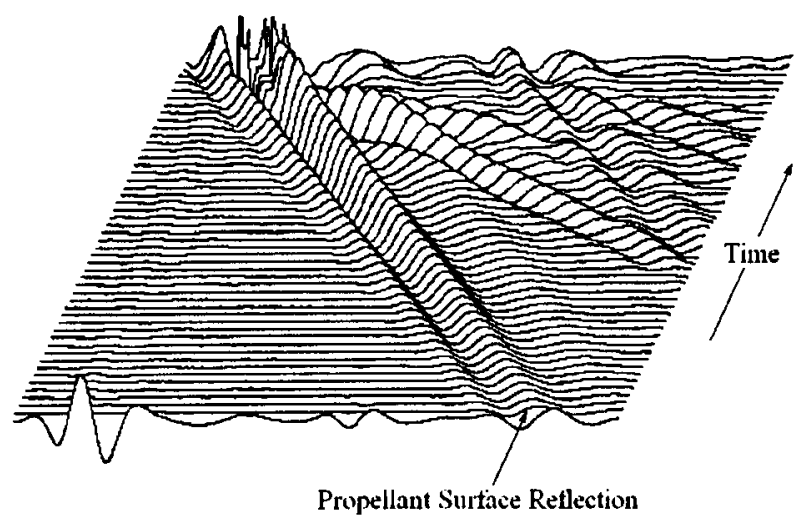

Figure 5: Return waveform waterfall after standing waves removed.

Validation of the ultrasonic instrumentation and evaluation of the speed of sound through the propellant at motor operating pressure was conducted using a single 5-inch CP motor segment. Testing a single segment permitted a comparison of the propellant burn rate from a ballistic analysis of the pressure trace and from the ultrasonic measurements of the propellant surface regression. Physical measurements of the ascast propellant web and a pressurized grain analysis were used to establish the starting web thickness for the ultrasonic burn rate evaluation. Comparison of the two techniques demonstrated agreement within $+/-0.003$ in/sec on burn rate.

\section{PRESSURE MEASUREMENTS}

Pressure measurements were evaluated at the head end on the motor, in the slots between each of the motor segments, and at the nozzle entrance. This provides a chamber pressure measurement on either end of the motor segment where the ultrasonic measurements are being made. To evaluate the static pressure at the mid segment propellant surface corresponding to the position of the ultrasonic instrumentation, upstream and downstream pressure measurements were averaged.

A CFD analysis was run on the tandem motor configuration to assess the error induced by using an average upstream and downstream slot pressure to represent the mid-segment static pressure. At a time slice of 0.14 seconds, Figure 6 , the computed pressure drop is shown. 


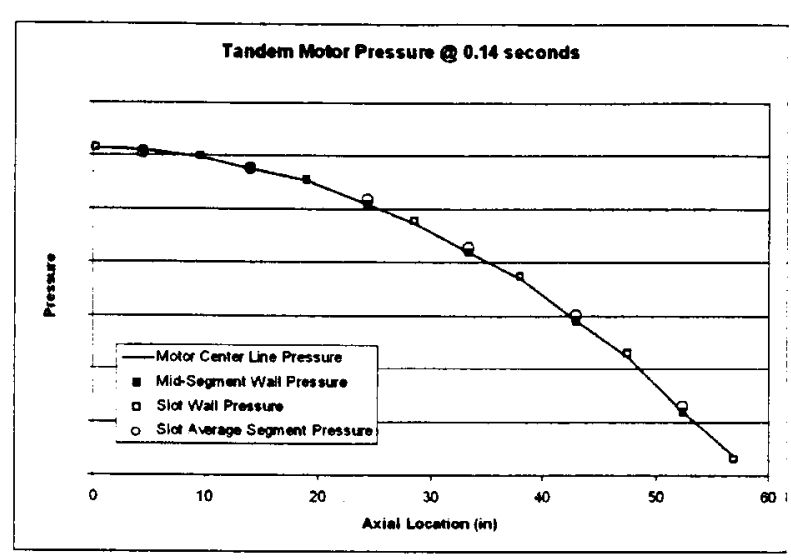

Figure 6: Mid segment pressure estimation error.

The computed center line, and mid segment static pressure is derived from a CFD analysis which has been correlated to measured slot pressure data. This analysis indicates that the maximum error resulting from using the average slot pressure to represent the mid segment static pressure is approximately 7-psia. This value, which approaches zero as the pressure drop in the motor dissipates, was determined not to be significant in the static propellant burn rate evaluation.

\section{SLOT FLOW DYNAMICS}

Concern about the influences of slot flow on down stream flow conditions was addressed. Flow out of the slots was analyzed with the same CFD model used to evaluate the mid-segment pressure measurement error and is presented in Figure 7.

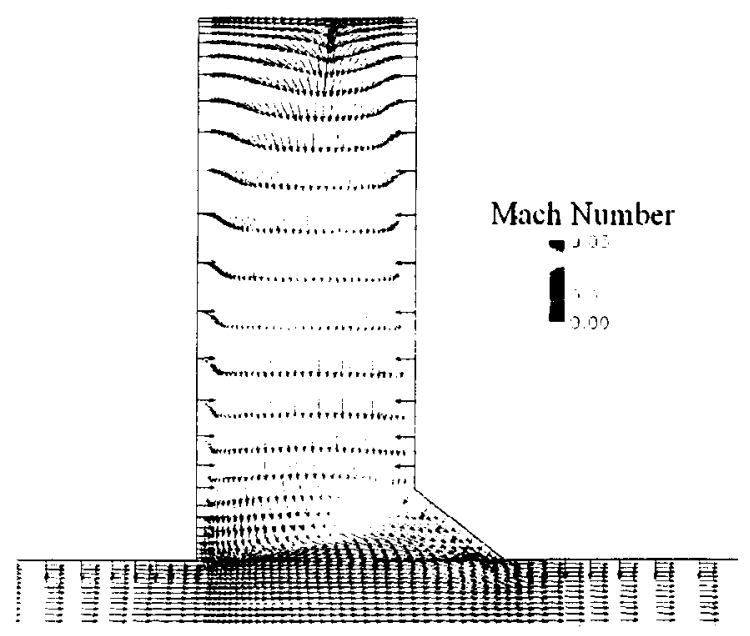

Figure 7: Slot flow velocity vectors.
Computed velocity vectors of the gas-flow out of a typical slot indicate that the emerging slot flow has sufficient time and space to turn in the direction of the bore gas-flow within the region of the grain chamfer. This supports the assumption that the slot flow should not significantly affect flow conditions at the propellant surface down stream from the slots.

\section{TEST RESULTS}

\section{PRESSURE DATA}

The measured pressure from the tandem motor tests is illustrated in Figure 8, Figure 9, and Figure 10, which represent motors cast with RSRM, Castor ${ }^{\circledR}$ IVA, and ETM-03 propellant, respectively. There is an obvious pressure blip observed in the pressure trace of Figure 9, which occurs approximately 1 second after motor ignition. This is believed to be the remnants of the igniter assembly exiting the nozzle. The igniter assembly consists of a phenolic tube sealed at the end with an epoxy plug. It is believed that occasionally the phenolic tube is consumed before the epoxy plug, which is then expelled out the nozzle. High-speed video of the tandem motor firings has captured debris exiting the nozzle at the corresponding time of the pressure blip. The timing of the event and the resulting pressure spike has been observed to be very consistent in those tandem motors in which it occurs. Multiple tests were conducted for each motor configuration and only a representative sample is included in this paper. Pressure blips were noted to be present equally among all the propellants tested.

Analysis of the measured pressure-time data indicates that the inflections in the motor pressure tailoff correspond with the burnout time of the tandem segments. The aft segments in some of the tandem test have been observed to burn out almost a full second before web time of the forward segment.

Analysis of the pressure data also indicates that an enhanced burn rate is present through a majority of the motor burn. The burn rate enhancement is a maximum at ignition and steadily dissipates as the propellant grain regresses. There were no sharp pressure spikes associated with the enhanced propellant burn rate. 


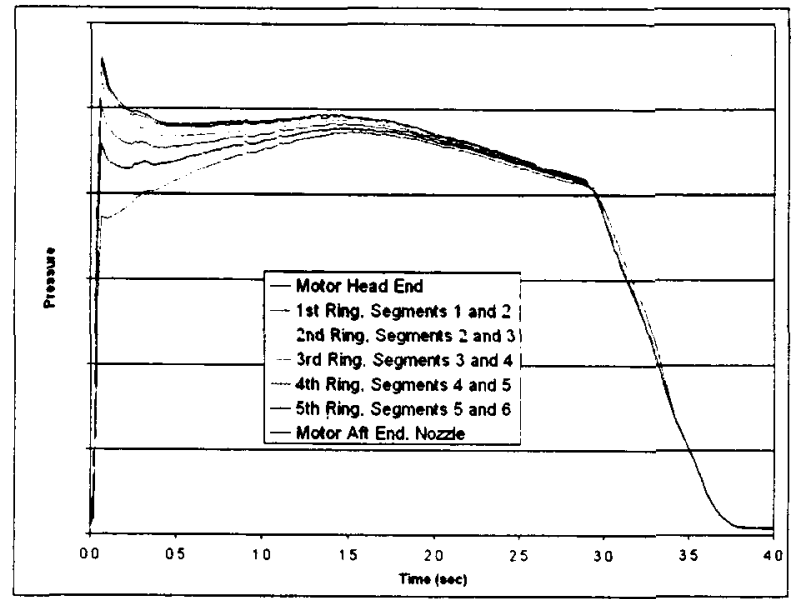

Figure 8: RSRM tandem motor pressure.

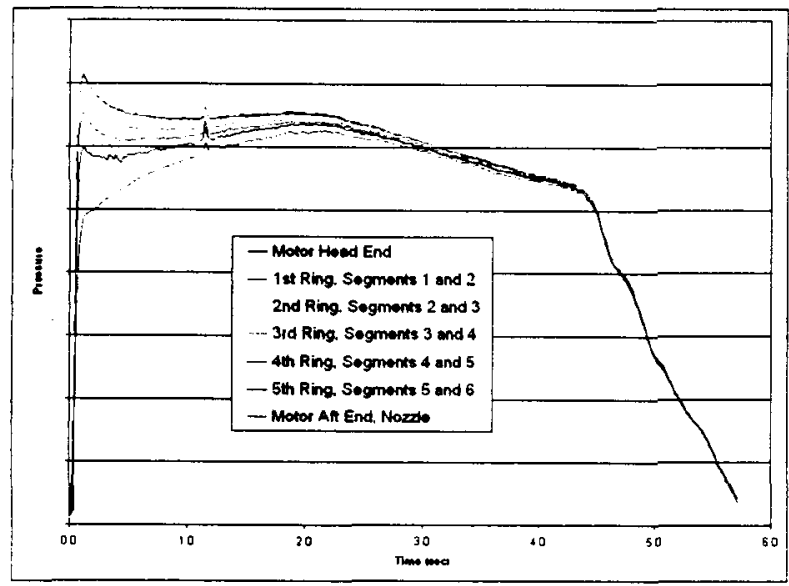

Figure 9: Castor ${ }^{\circledR}$ IVA tandem motor pressure.

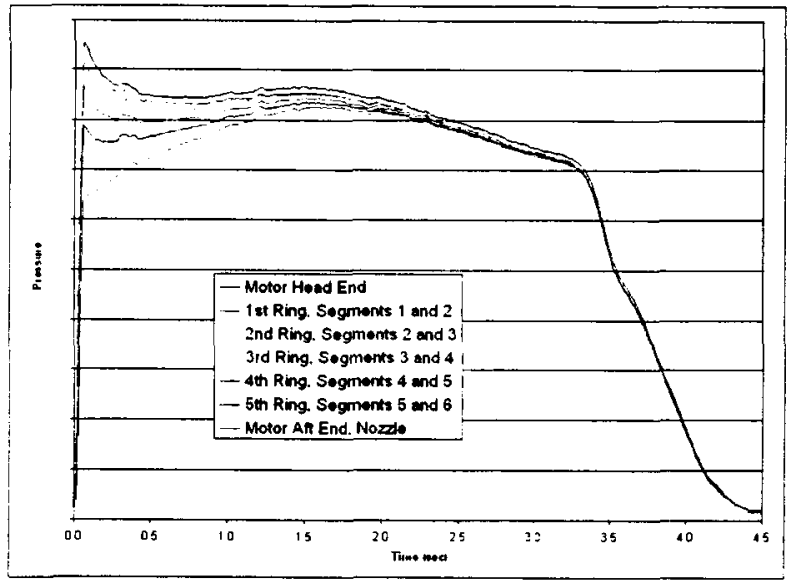

Figure 10: ETM-03 tandem motor pressure.

\section{ULTRASONIC DATA (BURN RATE VS TIME)}

The ultrasonic data was reduced according to the methods described to evaluate propellant burn rates. Results are illustrated in Figure 11, Figure 12, and Figure 13, which represent RSRM, Castor ${ }^{\circledR}$ IVA, and ETM- 03 burn rates, respectively. The data is presented with each segment's burn rate as a function of time to illustrate the magnitude of the burn rate enhancement along the length of the propellant grain during motor operation (segment 6 is aft most). The ultrasonic instrumentation extended into the propellant grain reducing the observable propellant web. Thus the termination of ultrasonic data indicates the time that the propellant web reached the vicinity of the ultrasonic instrumentation, approximately 0.75 -inches of web.

The aft two segments (segments 5 and 6) in the RSRM propellant tandem motor show a drop in burn rate from an enhancement of $60 \%$ to nominal burn rate values at a time of 0.3 seconds, Figure 11. Pressure data in the aft end of the motor at the time of the event indicates the presence of a tangential mode instability in the slot. It is suspected that the tangential mode instability in the slot provides some boundary layer relief to the down stream segments permitting recovery to the nominal burn rate. As pressure data indicates the dissipation of the tangential mode instability, ultrasonic surface regression measurements correspondingly indicate a re-establishment of the enhanced burn rate.

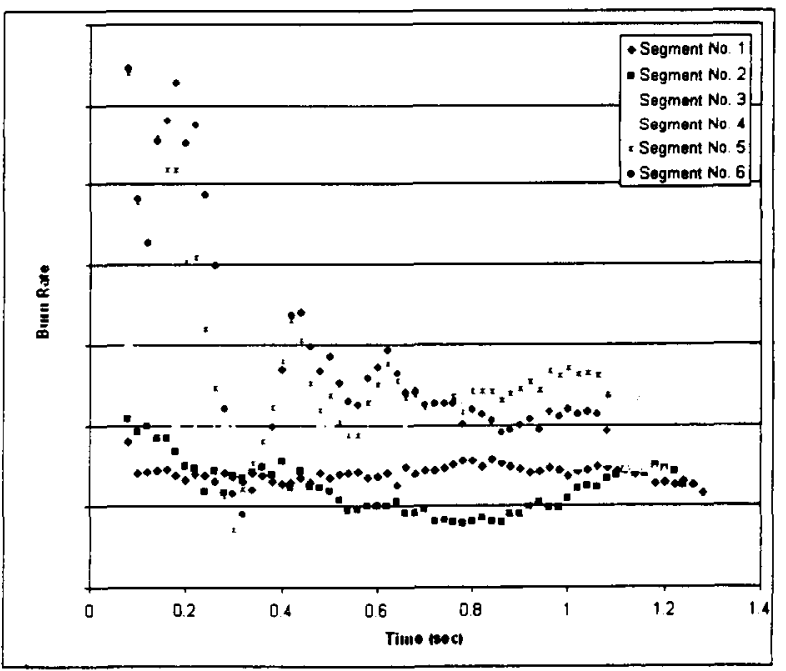

Figure 11: RSRM tandem motor burn rate vs time. 


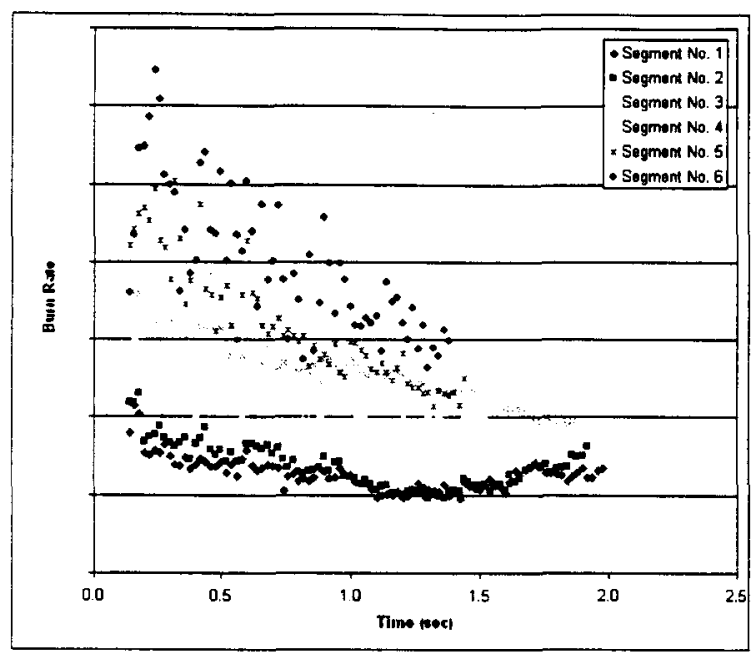

Figure 12: Castor $^{\circledR}$ IVA tandem motor burn rate vs time.

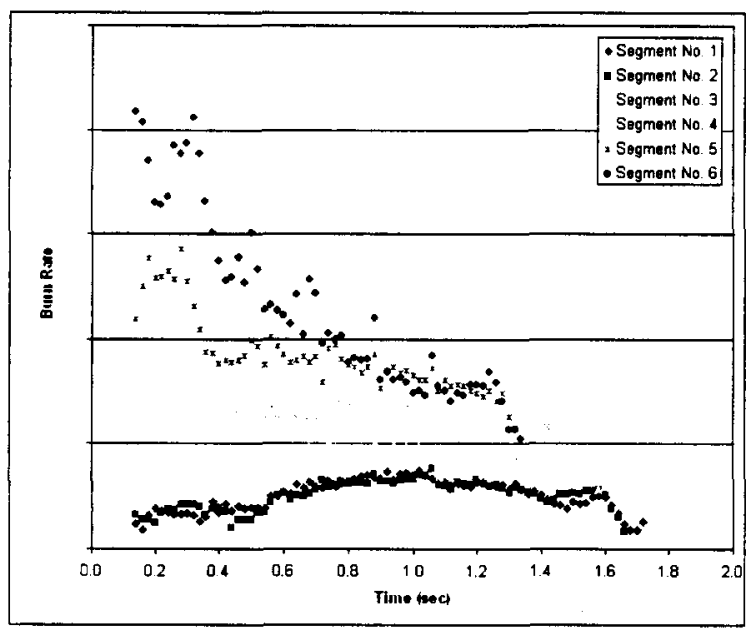

Figure 13: ETM-03 tandem motor burn rate vs time.

There is notably more data scatter in the ultrasonic surface regression measurements the further aft the motor segment. It is not known what contributes to the data scatter. However, there have been a couple of circumstances that have been proposed.

- The propellant burn rate is actually fluctuating as observed.

- The propellant surface is not regressing uniformly.

\section{ULTRASONIC DATA (BURN RATE VS MACH NUMBER)}

The extensive motor instrumentation, which includes pressure measurements along the length of the motor, and burn rate evaluations at the center of each segment, permitted a 1D correlation of burn rate versus Mach number to be computed for each tandem motor tested. Presented in Figure 14, Figure 15, and Figure 16 are the results of the burn rate versus Mach number correlation for RSRM, Castor ${ }^{\circledR}$ IVA, and ETM-03 propellants, respectively. Correlating propellant burn rate against a Mach-pressure product produced similar results to the Mach number correlation and are presented in Figure 17, Figure 18, and Figure 19 for RSRM, Castor ${ }^{\circledR}$ IVA, and ETM-03 propellants, respectively.

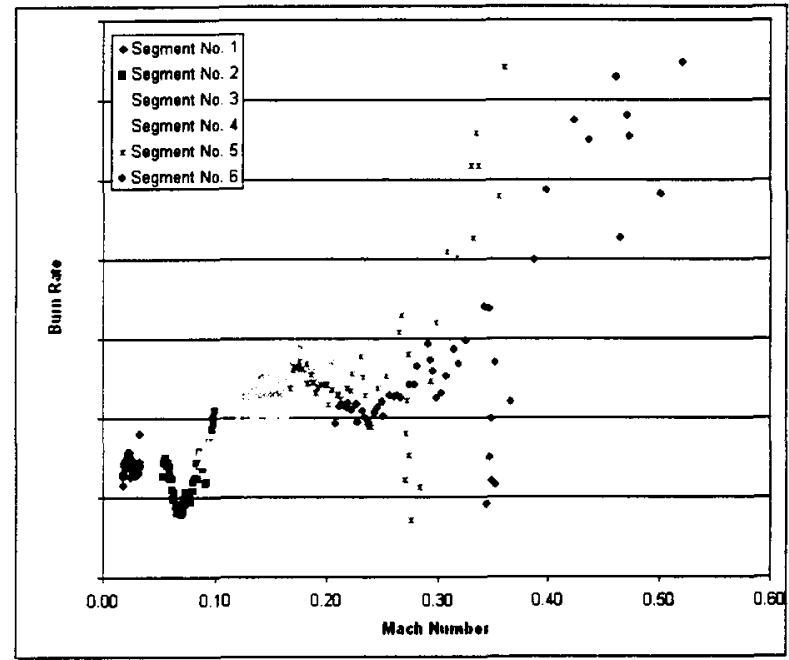

Figure 14: RSRM tandem, burn rate versus Mach Number.

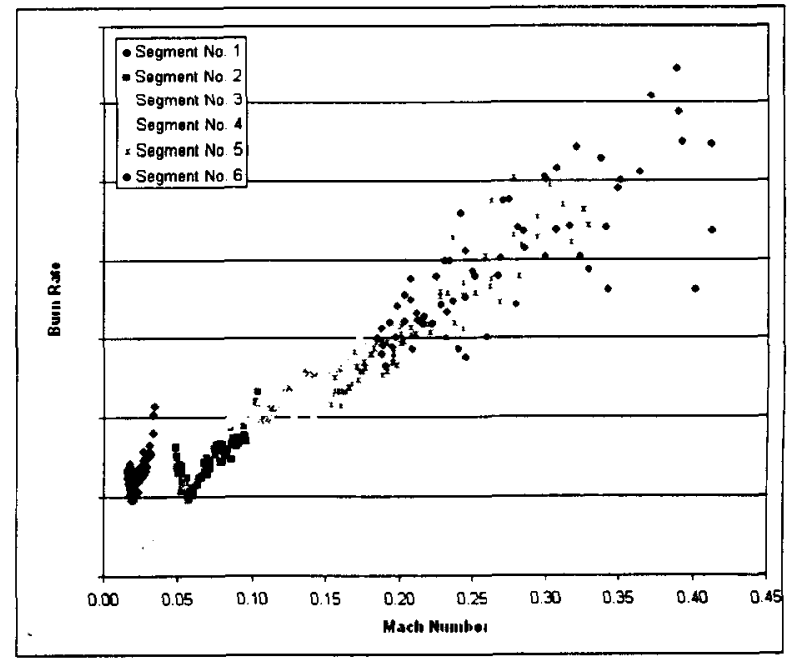

Figure 15: Castor ${ }^{\circledR}$ IVA tandem, burn rate versus Mach Number 


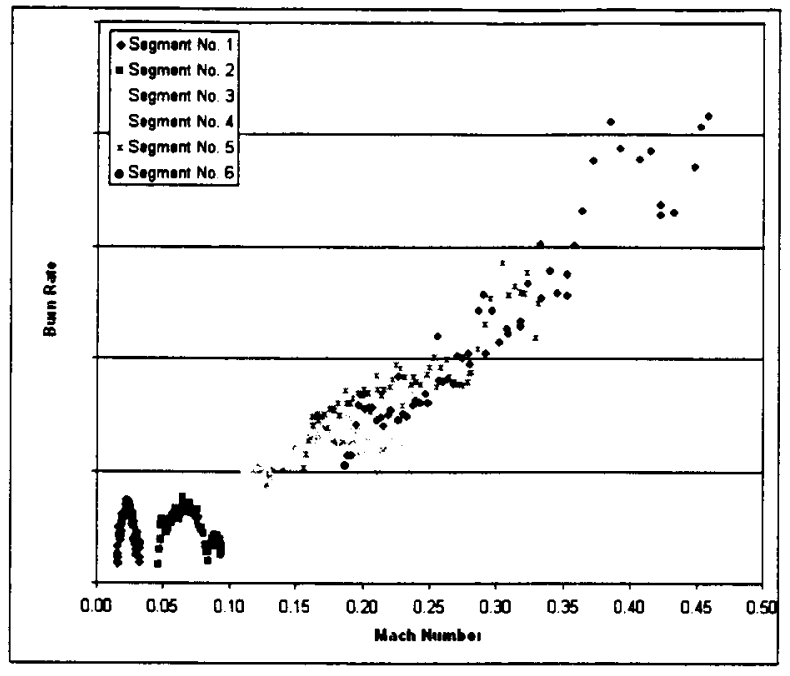

Figure 16: ETM-03 tandem, burn rate versus Mach Number.

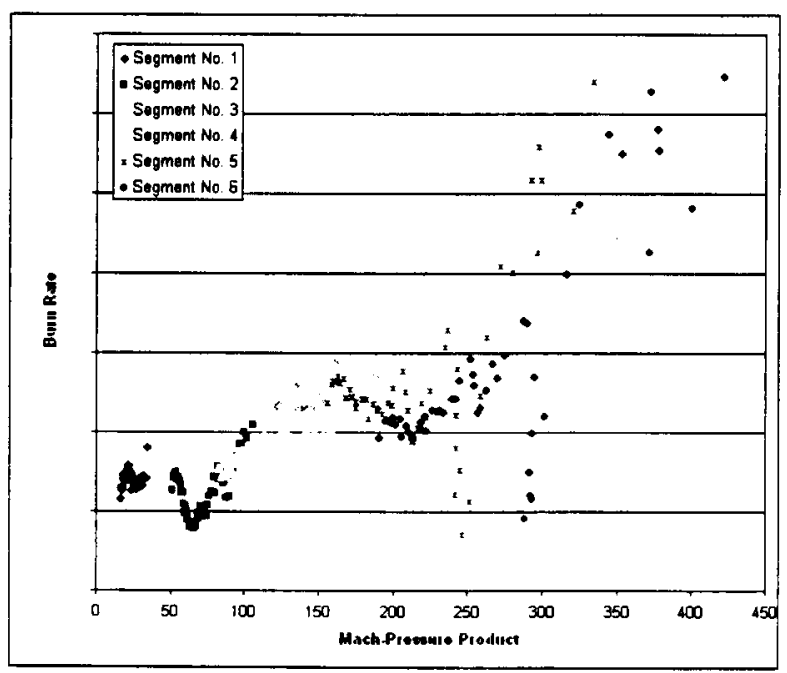

Figure 17: RSRM tandem, burn rate versus Machpressure product.

Similarities in the burn rate response show characteristics that have been noted by others studying the erosive burning phenomena. There is a definite threshold after which the propellant will exhibit an enhanced burning rate. This threshold is observed in both Mach and Mach-Pressure correlations. There also appears to be an intermediate range just beyond the threshold in which the propellant is responding to both chamber pressure and the bore flow Mach number.

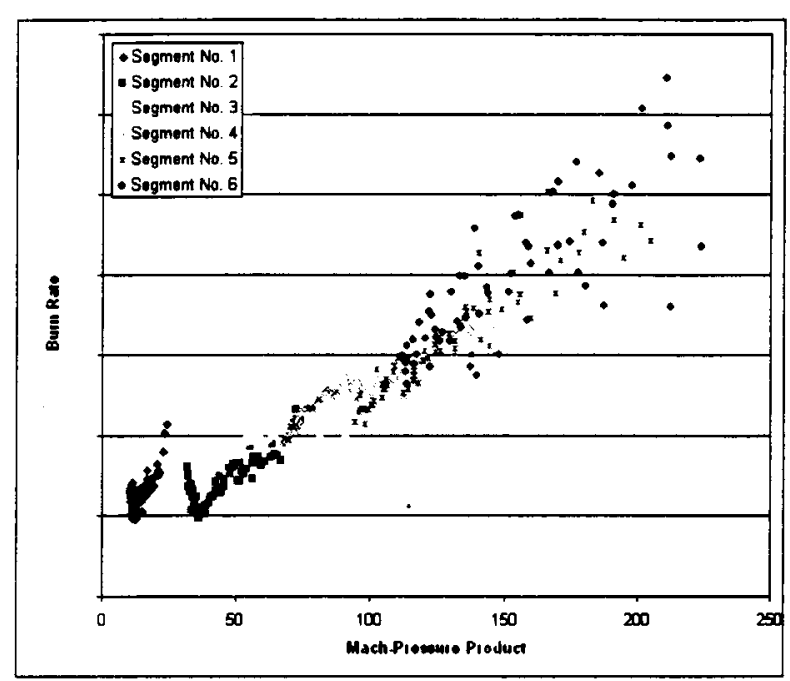

Figure 18: Castor $^{\circledR}$ IVA tandem, burn rate versus Mach-pressure product.

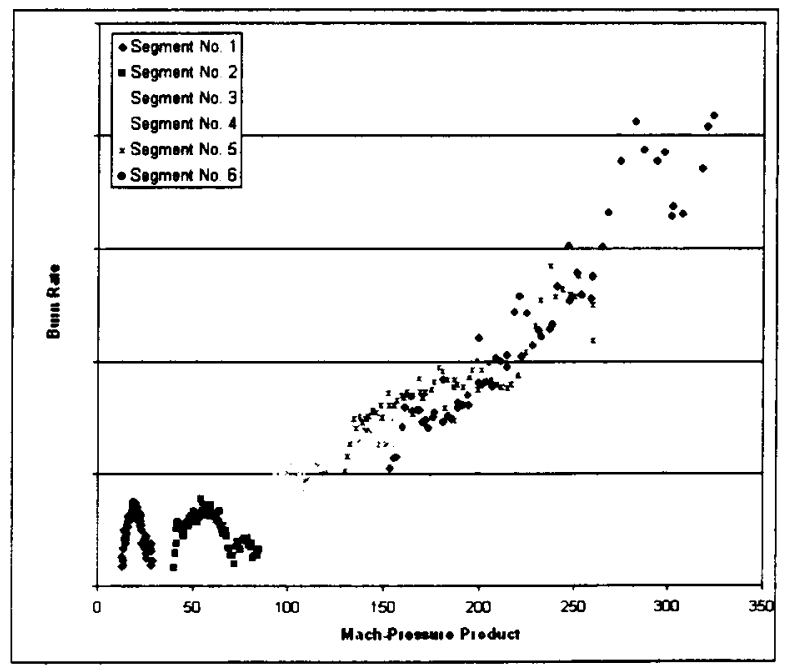

Figure 19: ETM-03 tandem, burn rate versus Machpressure product.

Segment 1 burn rates indicate the propellant response to pressure during motor operation. Segment 1 is at the head end of the motor and is not subjected to an enhanced flow environment. From the Mach and Mach-pressure product correlations it is obvious that segments 2, and 3 show indications of the first segment's burn rate profile at a higher base level. Segments 4, 5, and 6 are more linear in their response to the core flow Mach number and Mach-pressure product correlations. 
To compare burn rate enhancement of the three propellants, the collected burn rate data was normalized by subtracting the base burn rate from measured (burn rate at local static pressure) and shifting the threshold to zero on the Mach number axis. The threshold values used in the normalization are presented in Table 2. The threshold values show the beginning of a trend with respect to base burn rate. Higher base burn rates tend to have higher observed erosive thresholds. Other propellants not represented in this paper also support this trend, however, the number of propellants tested to date is limited.

Table 2: Burn rate thresholds.

\begin{tabular}{lccc}
\hline & RSRM & ETM-03 & Castor $^{\circledR}$ IVA \\
\hline $\begin{array}{l}\text { Mach Number } \\
\text { Erosive Threshold }\end{array}$ & 0.08 & 0.08 & 0.06 \\
$\begin{array}{l}\text { Normalized Burn } \\
\text { Rate }\end{array}$ & 1.0 & 0.93 & 0.70 \\
\hline
\end{tabular}

Results of the normalization are presented in Figure 20. The erosive responses of the propellants tested are very similar in their linearity and slope. This would suggest that the test data could support empirical correlations that are based on an erosive addition to the propellant base burn rate.

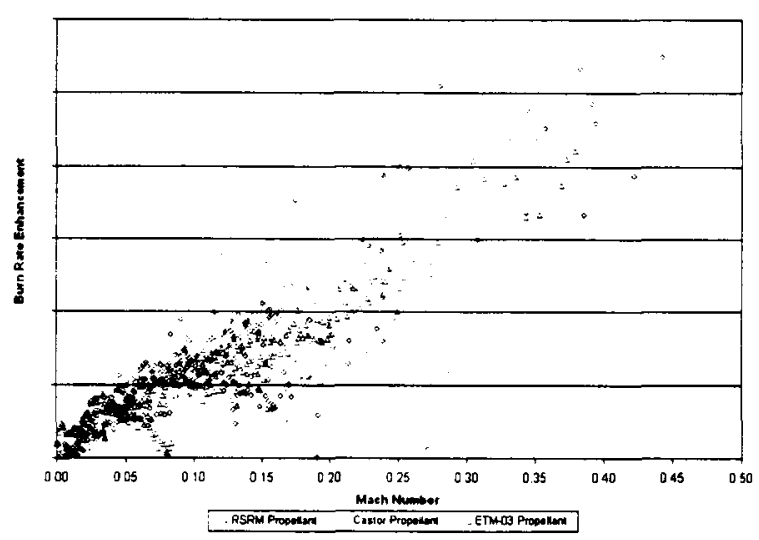

Figure 20: Enhanced burn rate comparison.

\section{CONCLUSIONS}

The ultrasonic burn rate measurement technique has demonstrated some pleasing accuracies for the forward and mid portions of the tandem motor. Data scatter in the aft portion of the motor (segments 5 and 6) may be linked to the motor configuration or the propellant surface condition during motor operation.

Burn rate enhancement data for the three propellants shows similarity after the data is normalized. Normalizing the data refers to compensating for base burn rate (burn rate at local static pressure) and threshold Mach number. Normalized data can be modeled empirically based on gas velocity, Mach number, or mass flux (Machpressure product). Similarity in the erosive response indicates that the propellant base type (HTPB or PBAN) is not a significant contributor for the range of environments tested in the tandem subscale motor.

Erosive burning response has been measured for three propellants over a pressure range spanning 400 psi. For the purpose of the test series this provided sufficient range to characterize the chosen propellant for ballistic evaluation in the ETM-03 motor design. Further studies need to be conducted to widen the pressure range to provide measured propellant erosive burning response data to assess pressure dependencies of the threshold Mach number. If the physical mechanism for the erosive threshold stems from a blowing wall heat transfer condition, then it is expected that the threshold will depend on pressure as well as base burn rate. 


\section{REFERENCES}

1) Huppi, H., Tobias, M., and Seiler, J., "Enhanced Large Solid rocket Motor Understanding Through Performance Margin Testing - RSRM five Segment Engineering Test Motor (ETM-03)," AIAA 2003-4958.

2) Wang, Q., "Development of Erosive Burning Models for CFD Predictions of Solid Rocket Motor Internal Environments," AIAA 2003-4809.

3) Furfaro, J. A., Laubacher, B. A., and Sauvageau, D. R., "Five-Segment Booster (FSB) Phase A Study Results," Presented at the $50^{\text {th }}$ JANNAF Propulsion Meeting July 12-13, 2001 Salt Lake City, Utah.

4) Strand, L., Yang, L., Nguyen, M., and Cohen, N., "Erosive Burning Research," AIAA 86-1449.

5) King, M. K., "Erosive Burning of Solid Propellants," Journal of Propulsion and Power," Vol. 9, No. 6, Nov-Dec. 1993, pp. 785-805.

6) Boardman, T. A., Porter, L. G., and Brasfield, F. W., "An Ultrasonic Fuel Regression Rate Measurement Technique for Mixture Ratio Control of a Hybrid Motor," AIAA Paper 95-3081, July 1995.

7) Porter, L. G., and Boardman, T. A., "Measurement of Fuel Regression Rate in Hybrid Motors Using a Digital Ultrasonic Technique," 1994 JANNAF Nondestructive Evaluation Subcommittee Meeting, CPIA Publication 616, Oct. 1994. pp. 11-23.

\section{ACKNOWLEDGEMENTS}

Other ATK Thiokol Propulsion engineers that contributed to the tandem motor testing are as follows:

Wayne Berndt (Ret.) Case Structural Analysis

Joe Hahne Case Structural Analysis

Brian Laubacher $\quad$ 2D CFD Flow Analysis

L. Grant Porter Ultrasonic Instrumentation

Greg Putnam Case Modification Design
Doug Smith

Mark Tobias

Quinn Wang
Ultrasonic Instrumentation

General Conception / Test Definition

2D CFD Flow Analysis 